\title{
ENGEVISTA
}

Página da revista: http://www.uff.br/engevista/seer/

\section{Setorização e Filtragem de Média Móvel na Análise Estatística do Sinal Rádio Móvel}

\section{Clustering and Moving Average Filtering on the Statistics of Radio Mobile Signal}

\author{
Vitor S. Pacheco ${ }^{1}$ \\ Leni J. Matos ${ }^{2}$ \\ Edson Cataldo ${ }^{3}$ \\ Wilyam D. T. Meza ${ }^{4}$
}

\begin{abstract}
Resumo: Este artigo compara as funções densidade de probabilidade (fdp's) obtidas segundo a técnica de setorização e da filtragem por média móvel sobre as potências das amostras de sinal rádio móvel adquiridas em ambiente indoor na faixa de $430 \mathrm{MHz}$. A distância entre as fdp's foi usada para compará-las, usando a métrica $\mathrm{L}^{1} \mathrm{e}$, então, conclusões sobre o número de amostras usadas nas janelas dos filtros são obtidas.
\end{abstract}

Palavras-chave: Desvanecimento; perda no percurso; filtro de média móvel; setorização.

\begin{abstract}
This article compares the probability density functions (pdf's) obtained through clustering and moving average filtering techniques applied on the power samples of the mobile radio signal acquired in indoor environment on the $430 \mathrm{MHz}$ range frequency. The distance between the pdf's was used to compare them, using the $\mathrm{L}^{1}$ metrics. And then, conclusions about the number of samples used in the filters windows were outlined.
\end{abstract}

Keywords: Fading; path loss; moving average filter; clustering.

\footnotetext{
${ }^{1}$ UFF - Universidade Federal Fluminense

${ }^{2}$ UFF - Universidade Federal Fluminense

${ }^{3}$ UFF - Universidade Federal Fluminense

${ }^{4}$ Universidad Peruana de Ciencias Aplicadas
} 


\section{Introdução}

Muitos são os autores que tratam da caracterização do canal rádio móvel nas diversas faixas de frequências [1], [2], [3], [4] e [5]. Na estimativa da média local para a análise estatística do desvanecimento de larga escala, as rotas sondadas são divididas em setores, que não devem ser muito pequenos porque acarretam erros excessivos, superestimando a média local, e nem muito grandes, pois as condições locais não mais se aplicam neste caso e a média local não é significativa [6]. Urie [6] chega à faixa de $5 \lambda$ a $40 \lambda$ para o tamanho desses setores, onde $\lambda$ é o comprimento de onda do tom transmitido no canal. Na prática, o que se faz é considerar o menor intervalo onde a média do sinal medido é praticamente constante, ou seja, um intervalo no qual a variação instantânea do sinal ocorra sobre um valor praticamente constante e isto é feito por inspeção visual do sinal expandido.

Yacoub [7] empregou um filtro passa baixas para a separação entre o sinal de variabilidade de pequena escala e o de larga escala somado ao path loss. Rolim [8] propôs o emprego da filtragem de média móvel na separação dos sinais de pequena e larga escala em vez da setorização. O que este artigo propõe é um estudo comparativo dos resultados da setorização e da filtragem de média móvel realizada no sinal faixa estreita, de forma a separar o sinal de larga escala, ou de média local, para estudar seu comportamento estatístico. Para tal, medições faixa estreita foram realizadas em ambiente indoor, com o transmissor posicionado tanto em ambiente indoor quanto outdoor, para caracterizar o canal rádio móvel na faixa de $430 \mathrm{MHz}$, que estava livre e era de melhor resposta para a taxa de onda estacionária da antena.

O artigo consta de 4 seções: a Seção II descreve o ambiente e o sistema de medições empregado; a Seção III descreve o processo de setorização, filtragem de média móvel (FMM) e processamento dos dados; a Seção IV apresenta os resultados com o uso das duas técnicas e a Seção V, as conclusões e trabalhos futuros.

\section{Ambiente e sistema de medições}

\subsection{Ambiente de medições}

A parte experimental foi realizada no Bloco E do Campus da Praia Vermelha da Universidade Federal Fluminense, na Escola de Engenharia. A sondagem foi dividida em três perfis distintos, descritos a seguir.

Perfil 1: A antena transmissora foi posicionada na parte externa do bloco E, e a estação receptora móvel (EM) se movimentou por todo o corredor do andar térreo desse bloco, sempre em visada direta com a transmissora. A Imagem 1 mostra a visada da antena transmissora para $o$ 
corredor sondado. Vai existir espalhamento no ambiente externo e muitos multipercursos no sinal recebido ao longo da rota, provindos das reflexões nas paredes, teto e chão do corredor.

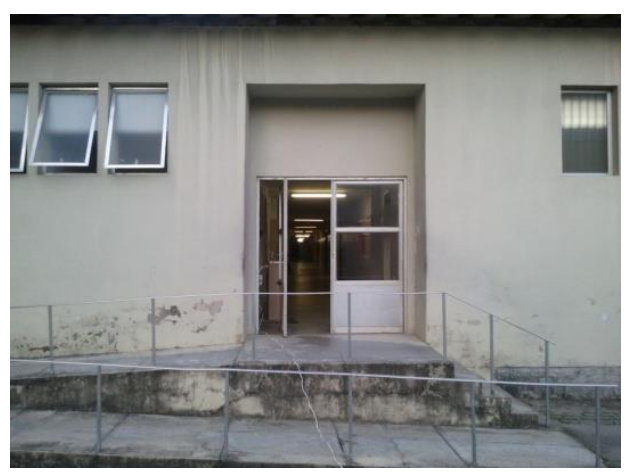

Imagem 1: Visada da antena transmissora para o Perfil 1.

Perfil 2: Antena transmissora posicionada no quarto andar do bloco E, em visada direta com a EM, esta se movimentando por todo o corredor. A Imagem 1 mostra a vista do ambiente pela antena transmissora.

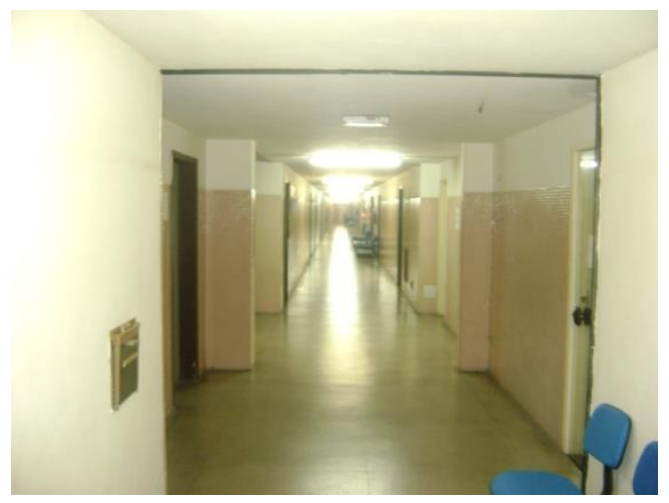

Imagem 1: Visada da antena transmissora para o perfil 2.

Perfil 3: Antena transmissora posicionada no Laboratório de Eletrônica, no quarto andar do bloco E, sem visada com a EM, à qual está percorrendo o mesmo corredor do Perfil 2. A Imagem 3 mostra o sistema transmissor dentro do laboratório, relativo ao Perfil 3.

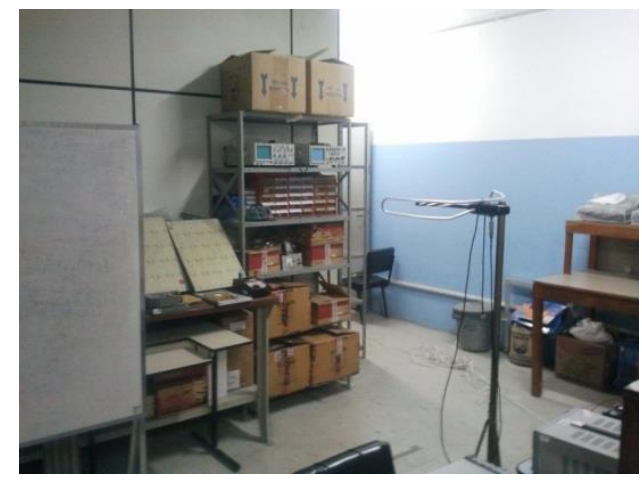

Imagem 3: Posicionamento da antena transmissora para o Perfil 3. 


\subsection{Sistema de medições}

As principais especificações para o sistema Transmissor-Receptor (Tx-Rx) são apresentadas na Tabela 1 e os diagramas unifilares do Tx e do Rx são mostrados na Imagem 4.

Tabela 1: Especificações do sistema Tx-Rx

\begin{tabular}{|l|l|}
\hline Transmissor & Receptor \\
\hline Gerador de Sinais R\&S SM300 & Analisador de Espectro HP 8594E \\
\hline $\begin{array}{l}\text { Antena Aquário DTV3000 tipo } \\
\text { Log-periódica, 6 dBi }\end{array}$ & Antenna Nagoya 144-430 MHz, G = 3 dBi \\
\hline $\begin{array}{l}\text { Amplificador de potência } \\
\text { ZHL-16W-43+ / G (430 MHz) }=21 \mathrm{~dB}\end{array}$ & Interface de aquisição DAQ Card-AI-16XE-50 \\
\hline Fonte digital PS5000 ICEL & Sensor de posição \\
\hline
\end{tabular}

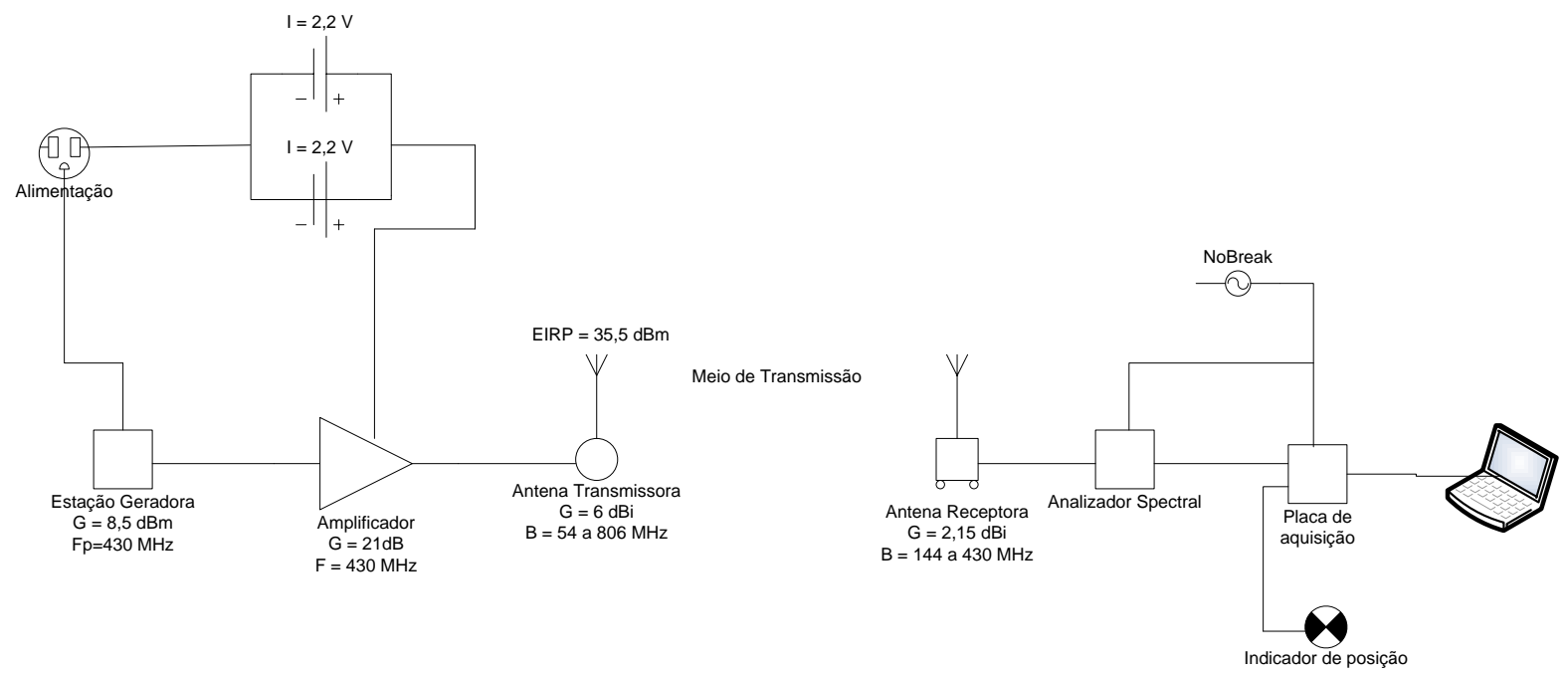

Imagem 4: Diagrama unifilar do sistema de transmissão e recepção. (Fonte: [9])

\section{Setorização e filttro de média móvel}

A técnica de setorização consiste na divisão do sinal medido na rota em setores de sinal, caracterizados por desvanecimento em larga escala, chamado de lento, praticamente constante [10] e [11], permitindo que se analise o desvanecimento em pequena escala, chamado de rápido. Para obter o desvanecimento em larga escala, é necessário calcular a média das amostras do sinal em cada setor, produzindo os pontos de média, que simbolizam a variação do desvanecimento lento do sinal. Para obter apenas o sinal de desvanecimento rápido, deve-se dividir cada amostra do sinal por sua correspondente média do setor (normalização) para retirar o efeito da perda com a distância e do sombreamento. Os setores aqui usados foram considerados de $10 \lambda$, portanto, dentro dos limites propostos por Urie [6], uma vez que a 
distância percorrida é curta, o que torna reduzida a quantidade de setores. No caso do Perfil 1, para este tamanho de setor, o tempo equivalente é igual a $7 \mathrm{~s}$, totalizando 14 setores, visto que a rota foi percorrida em 100 segundos. Os 12 primeiros setores foram tomados de 7 segundos e os 2 últimos, de 8 segundos cada.

A taxa de aquisição de dados considerada foi de 60 amostras/s, ligeiramente maior que $40 \mathrm{v} / \lambda$ ( $\mathrm{v}$ é a velocidade do móvel: $1 \mathrm{~m} / \mathrm{s}$ ), suficiente para que se possa observar os fadings profundos que possam ocorrer no sinal [12] e [13]. Foram adquiridas, portanto, 6000 amostras no Perfil 1 e, sendo a quantidade de amostras proporcional à duração do setor, tem-se 420 amostras para cada um dos doze primeiros setores e 480 amostras para os dois últimos.

Após a setorização do sinal, calculada a média das 420 amostras de sinal em cada setor, foram produzidos 14 pontos de média, que simbolizam a variação do desvanecimento lento do sinal acrescido à perda no percurso. Dividiu-se cada amostra do sinal por sua correspondente média do setor, retirando-se o efeito da perda com a distância e do sombreamento, obtendo-se apenas o desvanecimento rápido. A Imagem 5 exemplifica o sinal de variabilidade medido associado ao Perfil 1, assinalando as médias por setor. Raciocínio semelhante foi adotado para o Perfil 2 e Perfil 3.

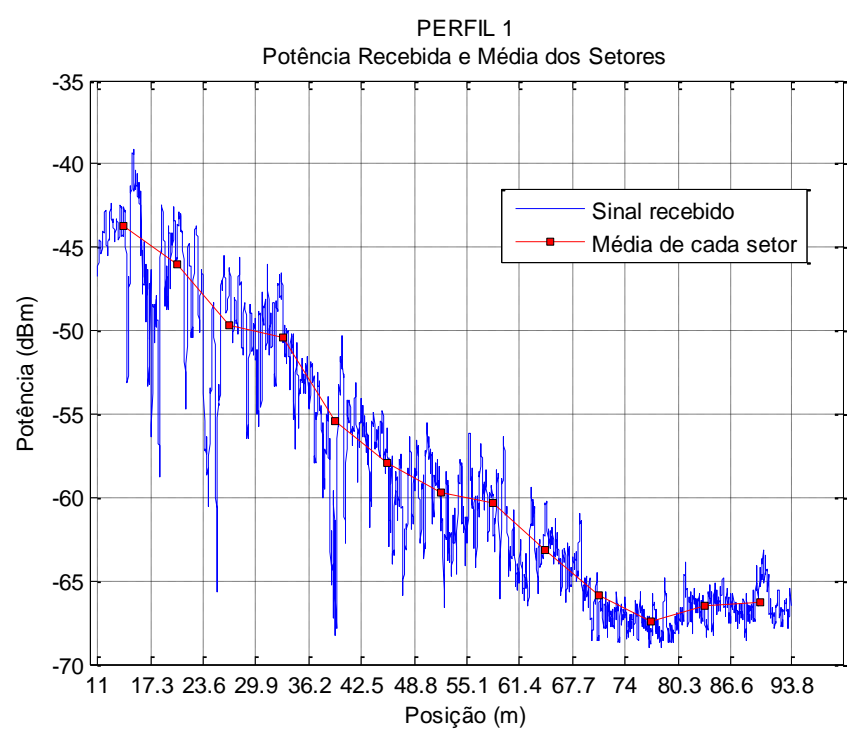

Imagem 5: Sinal de variabilidade associado ao Perfil 1.

O filtro de média móvel (FMM) [14] é um tipo de filtro usado, em geral, para minimizar o efeito do ruído embutido em um sinal. Como o sinal medido é aleatório, assim como um sinal de ruído, pode-se fazer uso do FMM para separar os sinais de desvanecimento tanto em pequena quanto em larga escala, bastando que se usem janelas de tamanhos adequados.

Neste trabalho, então, usa-se da filtragem de média móvel para separar as três principais componentes (a de pequena escala, a de larga escala e a perda no percurso) do sinal, visto à aleatoriedade do sinal recebido no ambiente móvel, acarretando na sua variabilidade. Foi 
escolhida uma janela móvel de tamanho $J$, a ser analisado adiante, que percorrerá as $N$ amostras do sinal, calculando a média aritmética entre as amostras pertencentes a esta janela e eliminando a sua variabilidade rápida, obtendo na saída do filtro um sinal com variabilidade menor do que o sinal de entrada, ou seja: obtendo um sinal mais suave, sem muita variação.

A Imagem 6 mostra o procedimento para a obtenção dos três efeitos do sinal separadamente. Após a passagem do sinal pelo $1^{\circ}$ filtro de média móvel (FMM1) obtém-se o sombreamento somado à perda no percurso $(\mathrm{S}+\mathrm{P})$. Pela diferença deste sinal ao sinal de entrada (SO), resta o sinal de desvanecimento em pequena escala (R), muitas vezes também chamado de componente Rayleigh (o que é verdade em muitos ambientes sem visada). Tomando-se o sinal de saída do FMM1 e colocando como entrada do FMM2, obtém-se apenas a perda no percurso (P) na saída do FMM2 e, subtraindo-se esse sinal do sinal de entrada do FMM2 (S+P), obtém-se a variação em pequena escala do sinal (S). Enfim, passando o sinal original por dois filtros de média móvel, é possível se obter os três principais efeitos separados do sinal de variabilidade: desvanecimento em grande escala ou sombreamento, desvanecimento em pequena escala e perda no percurso (S, R e P).

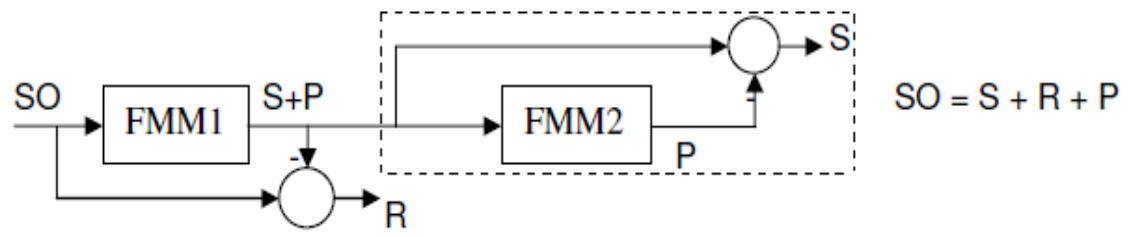

Imagem 6: Diagrama de blocos relativo às operações sobre o sinal medido.

\section{Processamento e resultados}

\subsection{Setorização}

Do Perfil 1, apresentado na Imagem 5, é obtido o sinal de desvanecimento em pequena escala, normalizado pela média de cada setor, e mostrado na Imagem 7, onde o efeito de perda com a distância foi extraído. O mesmo foi realizado para o Perfil 2, que aparece na Imagem 8 e na Imagem 9. A Imagem 10 e a Imagem 11 mostram, respectivamente, o sinal medido ao longo da rota e o sinal de variabilidade rápida, relativos ao Perfil 3. 
ISSN: $1415-7314$

ISSN online: 2317-6717

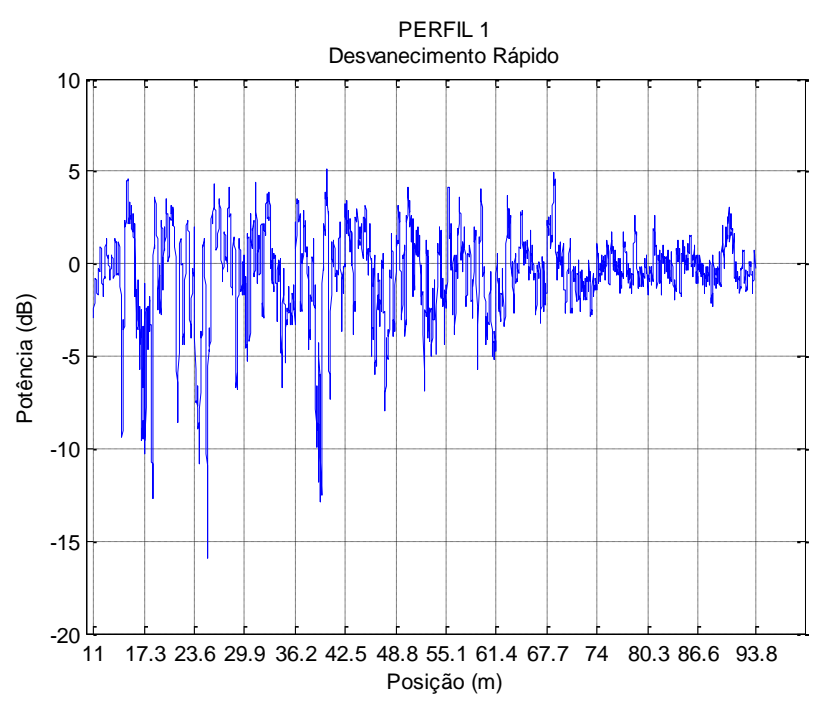

Imagem 7: Sinal de desvanecimento em pequena escala relativo ao Perfil 1.

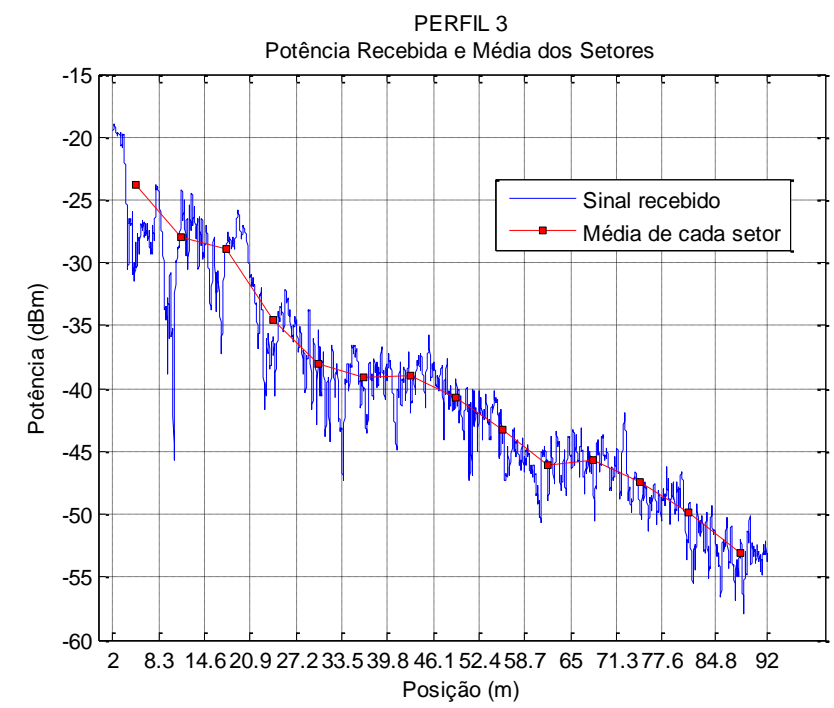

Imagem 8: Sinal de variabilidade associado ao Perfil 2.

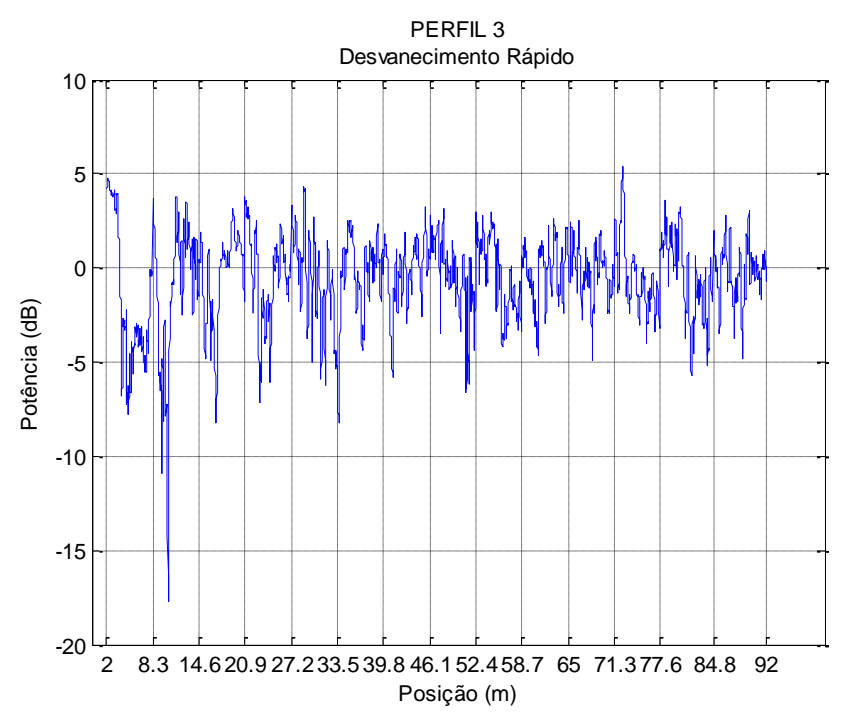

Imagem 9: Sinal de desvanecimento em pequena escala relativo ao Perfil 2. 


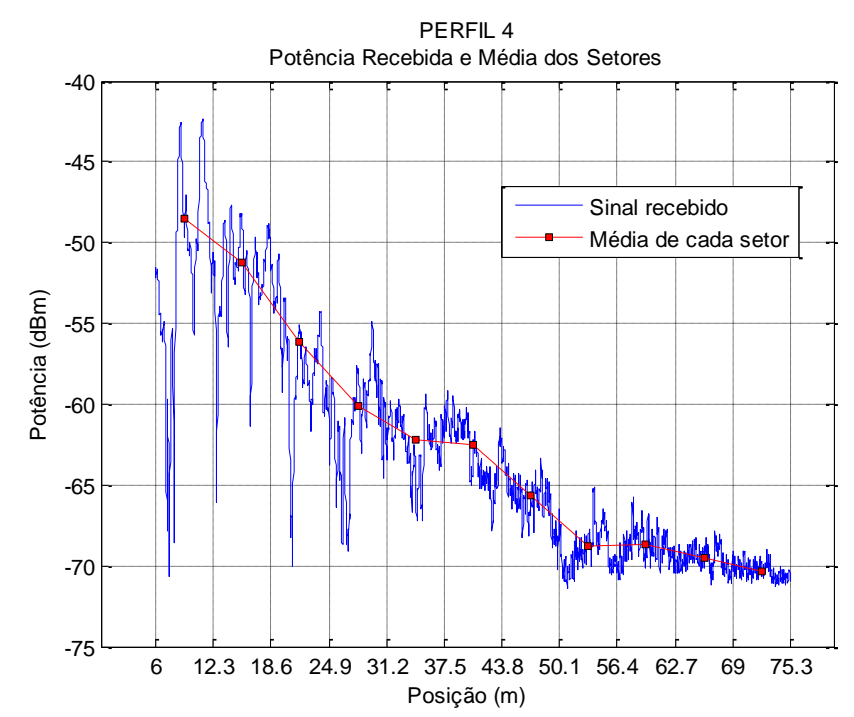

Imagem 10: Sinal de variabilidade associado ao Perfil 3.

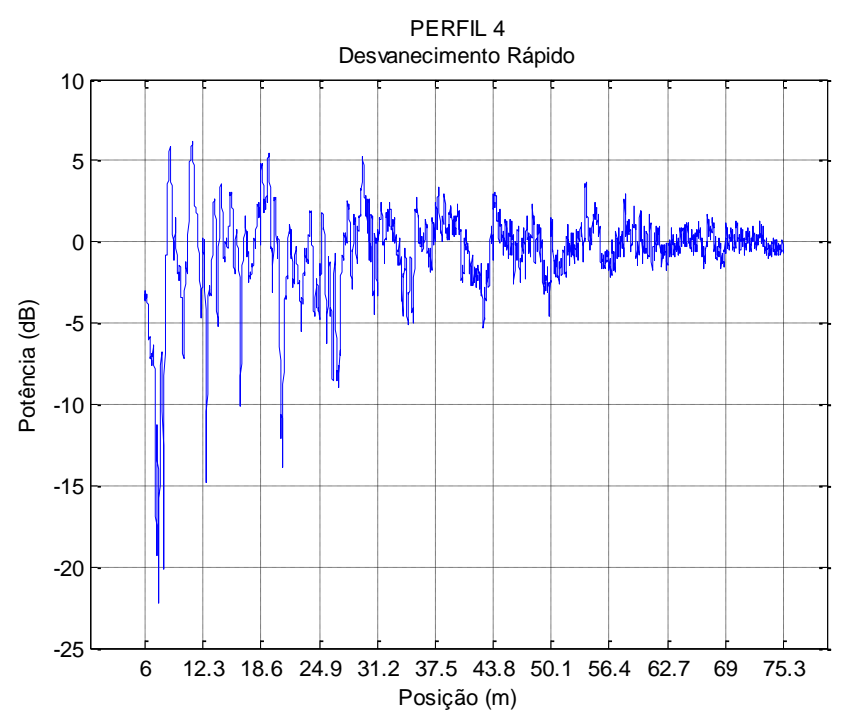

Imagem 11: Sinal de desvanecimento em pequena escala relativo ao Perfil 3.

\subsection{Filtro de média móvel}

Como dito anteriormente, um primeiro FMM é empregado para separar o desvanecimento em pequena escala do sinal original medido. É definido por (1):

$$
y[i]=\frac{1}{N+M+1} \sum_{k=-N}^{M} x[i+k]
$$

onde $i$ é o índice das amostras do FMM, y[i] é a $i$-ésima amostra de saída do filtro, $N$ é o número de amostras do sinal de entrada antes do ponto $i$ e $M$ é o número de amostras, consideradas no cálculo da média, após o ponto $i$ na janela móvel.

A partir do sinal de desvanecimento em pequena escala, extraído pelas duas técnicas, a de setorização e de FMM, são obtidas as distribuições estatísticas da tensão normalizada para todos os setores de cada perfil a fim de se comparar as técnicas através das estatísticas obtidas 
para o sinal de variabilidade medido. Antes, porém, o sinal de desvanecimento em pequena escala, obtido pelo FMM, necessita ser dividido (setorizado) para que se possa fazer uma comparação da distribuição estatística, setor a setor, com o sinal de desvanecimento em pequena escala obtido pela setorização.

Buscando-se verificar que tamanho de janela " $J$ " do FMM deveria ser usado para que as funções densidade de probabilidade (f.d.p.) nas duas técnicas se aproximassem o máximo possível, foi utilizada a métrica $L^{l}$ [15] e [16], que representa a diferença entre as f.d.p.s de um setor, para uma determinada janela, calculada por (1):

$$
D_{i}=\int\left|f d p(x)_{s e t}-f d p(x)_{F M M}\right| d x
$$

Ao fazer o cálculo da diferença para cada setor, através de $D_{i}$, é necessário somar essas diferenças, referentes a cada setor, para obter $S$, que representa o somatório das diferenças dos setores de um perfil, para um determinado tamanho de janela. O tamanho da janela escolhido é aquele que fornece o menor valor de $S$, que é representado por (3).

$$
S=\sum_{i=1}^{i=n} D_{i}
$$

A Imagem 12 exemplifica a curva obtida para o Perfil 1, indicando que o tamanho da janela ótima, que faz com que a diferença entre as curvas de densidades de probabilidade obtidas pela setorização e pelo filtro de média móvel seja mínima, é igual a 12 amostras, como se pode observar no ponto de mínimo da curva.

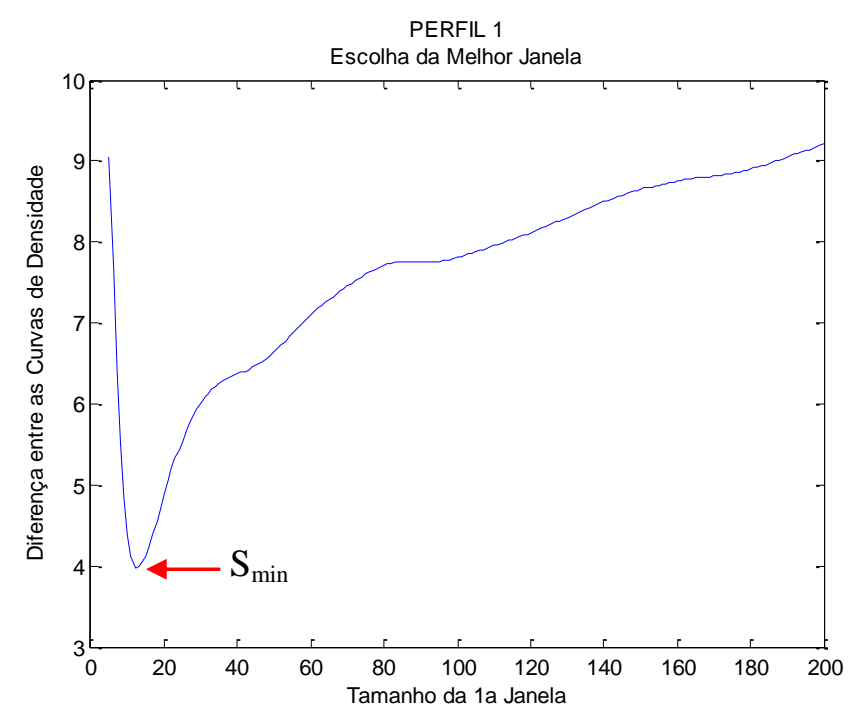

Imagem 12: Diferença entre as curvas de densidade para o Perfil 1.

A Imagem 13 compara as f.d.p.s obtidas pelas duas técnicas, relativa ao setor 4 do Perfil 1, para uma janela $J=12$ amostras usada no FMM. 


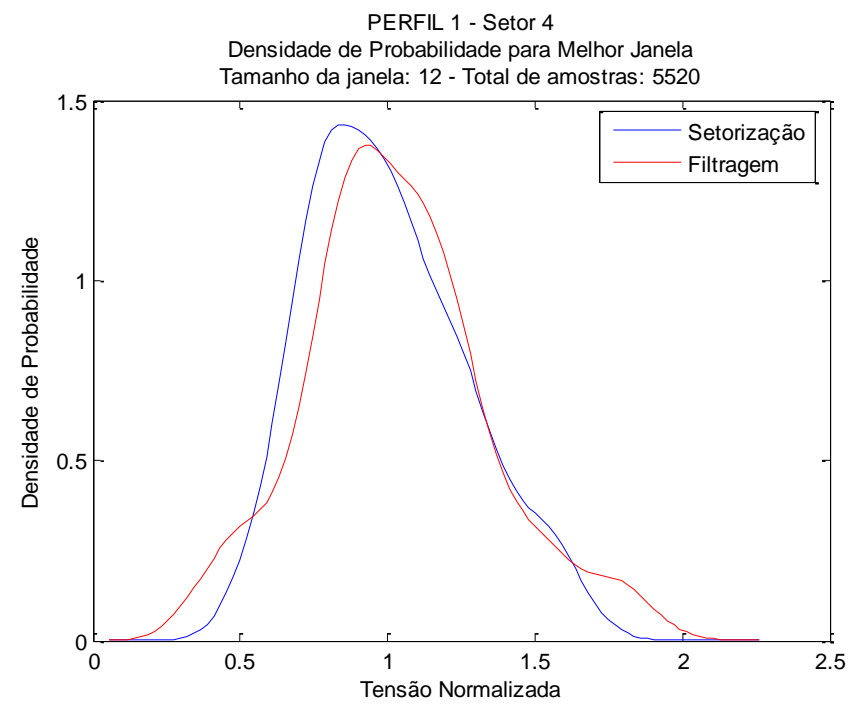

Imagem 13: Comparação das f.d.p.s obtidas pelas duas técnicas.

Para o Perfil 2, a janela ótima que faz com que a diferença entre as curvas de f.d.p., obtidas pela setorização e pelo FMM, seja mínima é a janela de tamanho igual a 14 amostras, como mostra a Imagem 14.

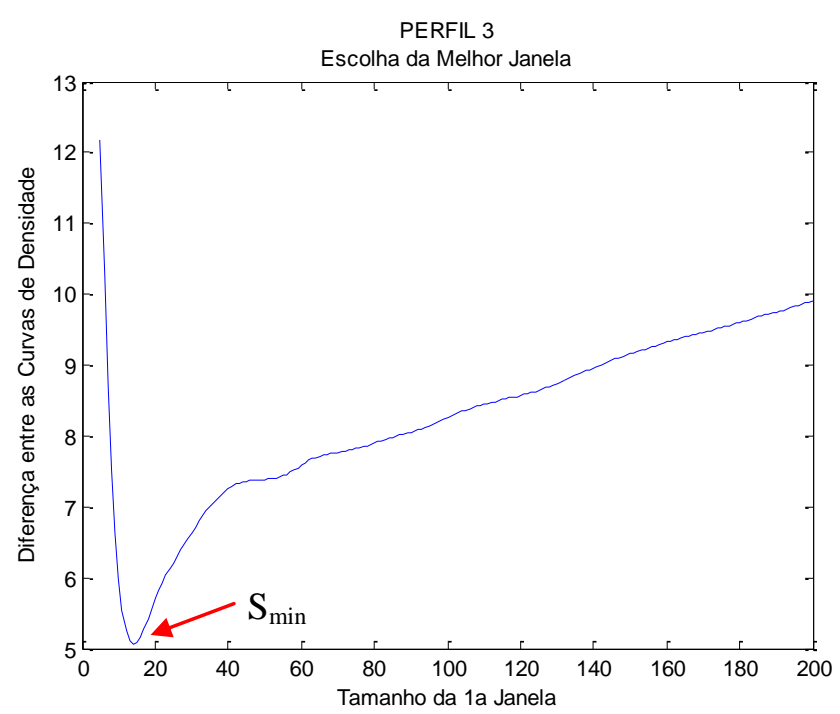

Imagem 14: Diferença entre as curvas de densidade para o Perfil 2.

Para o Perfil 3, a janela ótima é de 13 amostras, como se observa na Imagem 15.

No caso do desvanecimento em larga escala e da perda no percurso, há a necessidade de se empregar mais um FMM, entretanto, o número pequeno de amostras empregado na determinação da f.d.p. do desvanecimento em pequena escala mostra ser insuficiente para que os resultados entre as duas técnicas sejam próximos. Dessa forma, para obter o sinal de desvanecimento em larga escala somado à perda no percurso, um tamanho diferente de janela foi usado no primeiro filtro e a Imagem 16 exemplifica, para o Perfil 1, o sinal obtido pelas duas 
técnicas, em que o tamanho de janela de 420 amostras foi necessário para dar o menor erro entre elas.

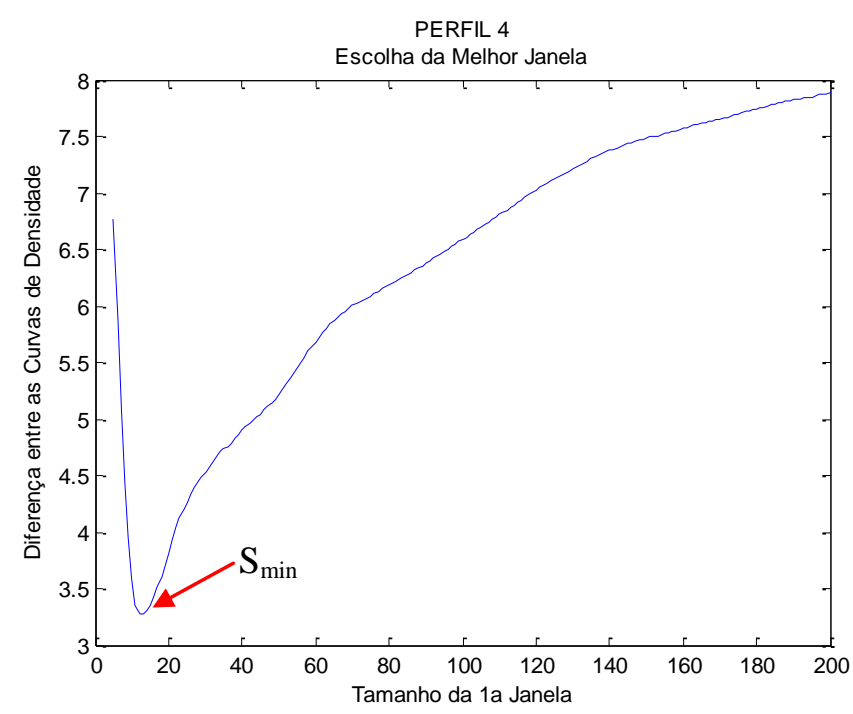

Imagem 15: Diferença entre as curvas de densidade para o Perfil 3.

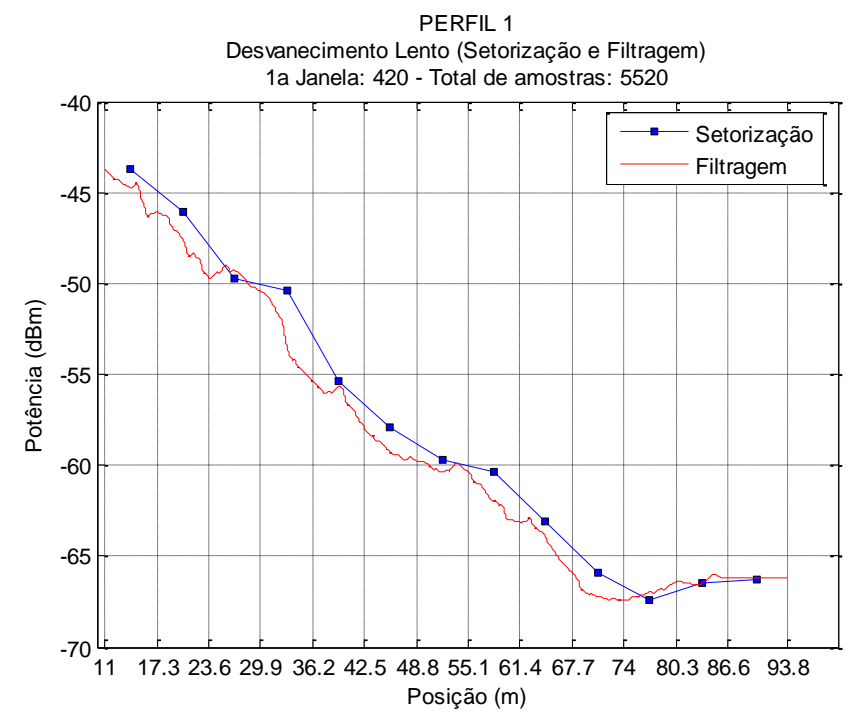

Imagem 16: Sinais $\mathrm{S}+\mathrm{P}$ obtidos pelas duas técnicas para o Perfil 1 .

Com processo semelhante, os sinais $(\mathrm{S}+\mathrm{P})$ foram obtidos para o Perfil 2 e o Perfil 3, nos quais as janelas empregadas para os filtros FMM1 e FMM2 foram as mesmas usadas para o Perfil 1, ou seja, 420 e 210 amostras, respectivamente. Os sinais de sombreamento (larga escala) somados às perdas no percurso obtidos estão traçados na Imagem 17 e na Imagem 18. Após sua obtenção, o segundo FMM de 210 amostras, permitiu retirar a perda no percurso. 


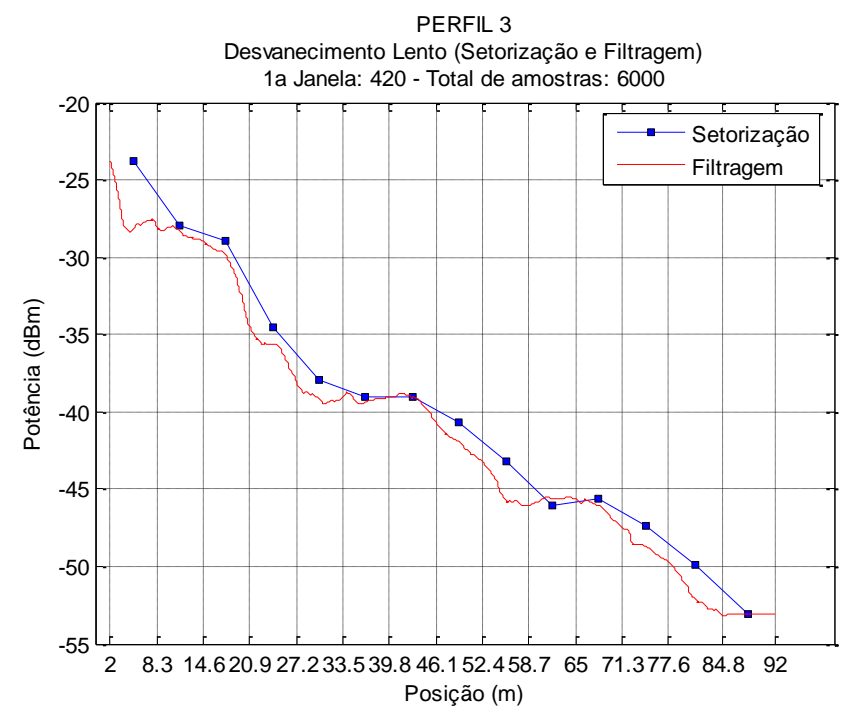

Imagem 17: Sinais $S+P$ obtidos pelas duas técnicas para o Perfil 2.

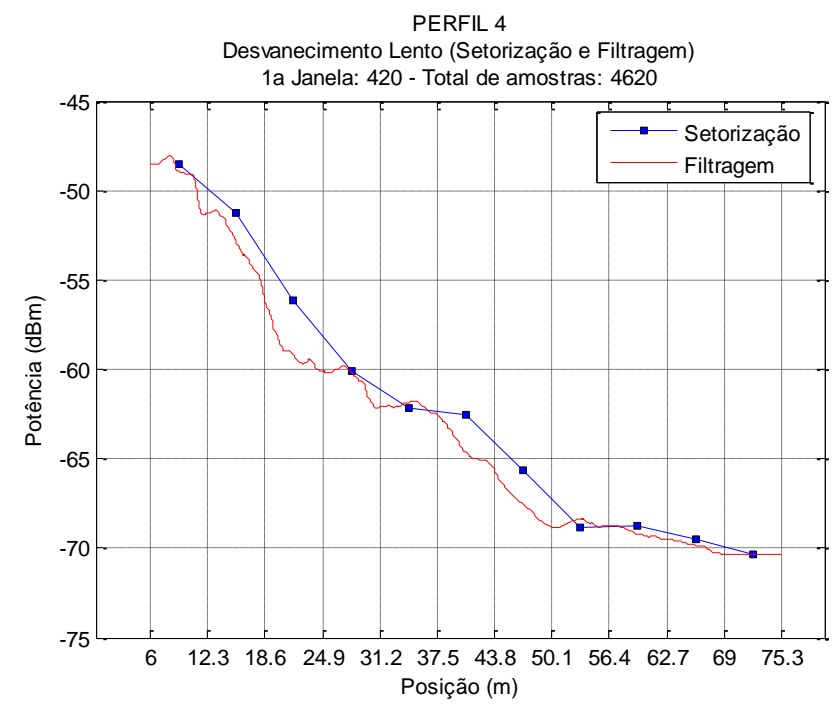

Imagem 18: Sinais $\mathrm{S}+\mathrm{P}$ obtidos pelas duas técnicas para o Perfil 3.

\section{Conclusões}

Dois filtros de média móvel, FMM1 e FMM2, foram aplicados ao sinal rádio móvel, medido em ambiente indoor, na faixa de $430 \mathrm{MHz}$, para a separação dos sinais de desvanecimento de pequena e larga escala.

Usando uma métrica que compara as funções densidade de probabilidade, obtidas para os sinais de desvanecimento, com as técnicas de setorização e filtragem de média móvel, este artigo conclui pelo tamanho das janelas necessário para realizar a análise estatística do sinal rádio móvel medido através da técnica do filtro de média móvel. 
$\mathrm{O}$ estudo mostrou que o sinal de sombreamento somado à perda no percurso exige um número elevado de amostras para o tamanho das janelas dos filtros FMM1 e FMM2, de forma a eliminar a variação de pequena escala do sinal. Para o ambiente indoor sondado, os melhores filtros foram de 420 e 210 amostras, respectivamente, entretanto, tais janelas não se adequaram para determinar a estatística de pequena escala, onde um número pequeno de amostras deve ser tomado de forma a não eliminar a variabilidade rápida do sinal. Para este fim, foram usadas janelas para o FMM1 de 14, 12 e 13 amostras, respectivamente, nos Perfis 1, 2 e 3.

Concluindo, o FMM é uma boa alternativa para a separação dos sinais $\mathrm{S}$ e R, de variabilidade em pequena e larga escala, respectivamente, entretanto, mais testes devem ser realizados, incluindo outras frequências e ambiente outdoor, para que se chegue a um fator comum para as dimensões das janelas empregadas em tais estatísticas.

\section{Referências}

[1] CHRYSANTHOU, C. \& BERTONI, Variability of Sector Averaged Signals for UHF Propagation in Cities, IEEE Trans. on Vehicular Tech., v. 39, N. 4, Nov. 1990, 352-358.

[2] RAPPAPORT, T. S. 1996. Wireless Communications - Principles and Practice, Prentice Hall.

[3] PARSONS, J. D. 2000. The Mobile Radio Propagation Channel, $2^{\text {nd }}$. Ed., John Wiley \& Sons.

[4] LEÃO, E. S. , FONSECA, F. J. B. \& MATOS, L. J., Análise Estatística da Variabilidade do Sinal Rádio Móvel Medido em Ambiente de Vegetação, $15^{\circ}$ SBMO - Simpósio Brasileiro de Micro-ondas e Optoeletrônica e $10^{\circ} \mathrm{CBMag}$ - Congresso Brasileiro de Eletromagnetismo, 2012, João Pessoa, Brasil.

[5] FONSECA, F. J. B., DIAS, P. P., DAL BELLO, J. C. R. \& MATOS, L. J., Variabilidade e Cobertura de Sinal Rádio-Móvel na Faixa de 3,5 GHz em Ambiente Urbano, $15^{\circ}$ SBMO Simpósio Brasileiro de Micro-ondas e Optoeletrônica e $10^{\circ}$ CBMag - Congresso Brasileiro de Eletromagnetismo, 2012, João Pessoa, Brasil.

[6] URIE, A. , Errors in estimating local average power of multipath signals, Electronics Letters, Feb. 1991, 315-317.

[7] YACOUB, M. D. 1993. Foundations of Mobile Radio Engineering, CRC Press.

[8] ROLIM, T. H. P., Vono, A. O., NOVAES, C. D. \& Guimarães, D. A., Um Método para Síntese e Análise dos Principais Efeitos de Propagação em Canais de Rádio Móvel, Revista de Telecomunicações - Inatel, v. 5, N. 1, 2002, 35-40.

[9] PACHECO, V. S., CATALDO, E. \& MATOS, L. J., Emprego da filtragem de média móvel na análise estatística do sinal rádio móvel, na faixa de $430 \mathrm{MHz}$, em ambiente interno, Dissertação de mestrado, UFF, Niterói, 2012.

[10] LEE, W. C. Y. 1982. Mobile Communications Engineering, Mc Graw Hill.

[11] LEE, W. C. Y., Estimate of Local Average Power of a Mobile Radio, IEEE Trans. Vehicular Technology, v. 34, Feb. 1985, 22-27.

[12] MACHADO, D. G.2010. Análise estatística do desvanecimento rápido. Aplicação a um sinal rádio móvel de 1,75 GHz, em ambiente LOS indoor. Escola de Engenharia, UFF, Niterói.

[13] VÁSQUEZ, E. J. A. 1996. Estudo de cobertura de sistemas móveis celulares em regiões urbanas, Dissertação de Mestrado, PUC-RJ.

[14] PROAKIS, J. G. 2000. Digital Communications, $4^{\text {th }}$ Ed., Mc Graw-Hill.

[15] LIMA, E. L. 1983. Espaços Métricos, 2a. Ed, IMPA, RJ. 
ISSN: $1415-7314$

ISSN online: $2317-6717$

[16] SOUZA, T. M. 2011. Análise da Cobertura e Variabilidade de Sinal Rádio em um Ambiente Interno na faixa de 1,9 GHz, UFF, Niterói. 